\title{
Histoire de l'architecture et des jardins du Japon pré-moderne (milieu du XVI ${ }^{\mathrm{e}}$ siècle- milieu du XIX ${ }^{\mathrm{e}}$ siècle)
}

\section{Nicolas Fiévé}

\section{OpenEdition} Journals

Édition électronique

URL : https://journals.openedition.org/ashp/899

DOI : 10.4000/ashp.899

ISSN : 1969-6310

Éditeur

Publications de l'École Pratique des Hautes Études

\section{Édition imprimée}

Date de publication : 1 octobre 2009

Pagination : 393-395

ISSN : 0766-0677

\section{Référence électronique}

Nicolas Fiévé, « Histoire de l'architecture et des jardins du Japon pré-moderne (milieu du xve ${ }^{e}$ sièclemilieu du xIx ${ }^{\mathrm{e}}$ siècle) », Annuaire de l'École pratique des hautes études (EPHE), Section des sciences 


\title{
HISTOIRE DE L'ARCHITECTURE ET DES JARDINS DU JAPON PRÉ-MODERNE (MILIEU DU XVI ${ }^{e}$ SIÈCLE-MILIEU DU XIX ${ }^{\mathrm{e}}$ SIÈCLE)
}

\author{
Directeur d'études : M. Nicolas FIÉvÉ
}

Programme de l'année 2007-2008 : L'architecture palatiale et les jardins de Kyōto (XVI ${ }^{e}$ XVII ${ }^{e}$ s.).

Plusieurs styles de l'habitat noble ont été identifiés par les historiens de l'architecture pour la période pré-moderne : le shinden-zukuri 寝殿造り pour les palais de la cour impériale, le shoin-zukuri 書院造り pour les yashiki 屋敷 des chefs militaires, le sukiya-zukuri 数奇屋造り pour les ermitages et les villas de plaisance bâtis alentour de la capitale. Enfin, quelque peu à part, les grandes maisons de ville des marchands (machiya 町家). Sans remettre en cause les différences formelles de chacun de ces styles, une relecture critique de ces architectures, fondée sur l'étude des plans de palais et de grandes demeures, a cherché à mettre en évidence un ensemble cohérent de pratiques et d'ordonnancements communs à ces architectures. Entre le $\mathrm{XV}^{\mathrm{e}}$ siècle et le XVII siècle, l'intelligence collective a élaboré une organisation originale de l'espace habité qui a dépassé les clivages stylistiques. Que l'on fût aristocrate, kuge 公家, guerrier, buke 武家, voire riche bourgeois, chōnin 町人, l'organisation des demeures a fait appel à un même ensemble de dispositifs spatiaux.

Afin d'introduire l'histoire de l'architecture noble de la période pré-moderne dans une large perspective et de sensibiliser les auditeurs à des problématiques spécifiques à l'architecture japonaise, la conférence a présenté les fondements de l'habitat noble en remontant aux modèles anciens et médiévaux. Le modèle antique de l'architecture aristocratique a inspiré l'architecture des palais de Kyōto jusqu'au XVI $\mathrm{X}^{\mathrm{e}}$ siècle et sa place devient prépondérante dans les reconstructions du palais impérial de l'époque pré-moderne. On a ainsi étudié les plans d'édifices représentatifs de l'architecture de leur époque : parmi ceux-ci, Higashisanjō-dono 東三条殿 et Kaya no in 高陽院, pour l'époque ancienne et l'architecture aristocratique, dont les ordonnancements et les structures furent dans un second temps comparés aux plans des palais Kitayama-dono 北山殿 et Higashiyama-dono 東山殿 des shoguns Ashikaga, demeures datant de la fin du XIV siècle et du XV siècle.

Après un tour d'horizon sur l'architecture palatiale du Moyen Âge - organisation des plans, structures des bâtiments, techniques de construction, décorations des intérieurs, inventaire du mobilier de partition des espaces (parmi lesquels volets, cloisons amovibles, portes à battant, portes coulissantes, stores, voiles sur trépieds, rideaux, écrans, paravents) -, on s'est intéressé au jardin et à sa relation avec les habitations. Depuis l'époque ancienne, le jardin a représenté un paysage en miniature. Des motifs pittoresques, hérités de la Chine et parfois fondés sur des éléments de la vision indienne 
de l'univers que véhiculait le bouddhisme, avaient été associés à des cultes locaux de la nature, ce qui a engendré les fondements stylistiques du jardin japonais.

Les paysages représentés dans les jardins de Kyōto imitaient parfois des sites réels du Japon ou de la Chine, le plus souvent des paysages légendaires. Dans ce domaine, l'apport chinois des croyances taoïstes s'est exprimé dans le thème des shinsen 神仙, les ermites doués de pouvoirs supérieurs qui vivaient dans des montagnes (sanshinzan 三神山) ou des îles fabuleuses (santō 三嶋) situées au-delà la mer de l'Est. Les trois monts Penglai (jap. : Hōrai 蓬莱), Yingzhou (jap. : Eishû 瀛州) et Fangzhang (jap. : Hōjō 方丈), auxquelles les Japonais avaient associés les sites sacrés des monts Fuji 富士, Atsuta 熱田 et Kumano 熊野, ont été très souvent symbolisés dans les jardins de Kyōto, comme au milieu de l'étang du monastère Tenryûji 天龍寺 ou de celui du palais de Kitayama. Les ermites qui siégeaient sur ces montagnes étaient censés détenir le secret d'élixirs de jouvence et d'immortalité, et celui qui figurait dans son jardin leurs demeures, en imitant les trois montagnes émergeant de la mer, devait lui aussi bénéficier d'une longue vie. Les conceptions taoïstes liées à la longévité se japonisèrent, elles donnèrent naissance au couple de l'île-grue, tsuru-jima 鶴嶋, et de l'île-tortue, kamejima 亀嶋. Sur les îles et les monts s'enracinaient le plus souvent des pins immémoriaux (Senzui narabi ni yagyō no zu 山水並野形圖 [Traité illustré sur les paysages], copie de 1466 conservée au temple Ninnaji). Selon d'anciennes conceptions, le vieux pin, qui devient lui-même tortueux au fil des ans, ressemble à la grue et à la tortue. Pour les Chinois, la longévité légendaire attribuée à cette plante et à ces animaux - le pin, la grue et la tortue peuvent vivre plusieurs milliers d'années - provenait de techniques qui se préoccupent de l'allongement des vaisseaux, de l'affinement du souffle et du ralentissement de la sève. La grue et la tortue l'obtenaient par l'étirement du cou et de leurs membres, le pin par la torsion de ses branches, phénomène qu'amplifiait davantage la nanification artificielle d'un arbuste. Inséparables, la pierre et le pin étaient considérés par les chinois de la même essence. Uni à la roche, le pin obtenait avec l'âge des vertus médicinales et magiques. De même, les très vieux objets avaient une plus grande valeur, parce qu'ils offraient une concentration de leurs vertus. Avec le temps, les propriétés ordinaires se transforment en propriétés rares et précieuses. C'est là une des raisons pour lesquelles on trouve au Japon comme dans tout l'ExtrêmeOrient sinisé des vieux arbres et des roches dans l'enceinte de temples ou de sanctuaires, dont le culte sert avant tout à demander la guérison, la santé et la postérité. L'usage des plantes nanifiées, plantées à même la terre ou présentées dans des bassins, bon$s a i$ 盆栽, ou de pierres dressées dans le jardin ou présentées dans des bassins, bonsan 盆山, devint un des motifs privilégiés du jardin japonais.

Après un détour sur les thèmes paysagers des jardins médiévaux, on s'est interrogé sur l'évolution des modes de vie au cours du $\mathrm{XV}^{\mathrm{e}}$ siècle et ses conséquences sur l'architecture palatiale de Kyōto. Les $\mathrm{XV}^{\mathrm{e}}$ et $\mathrm{XVI}^{\mathrm{e}}$ siècles ont été une période de mutation, où furent mises en place de nouvelles organisations spatiales de la capitale, des villes seigneuriales et de l'architecture domestique des élites, réorganisées à l'image d'une société dominée par la classe des guerriers. On a constaté que les demeures des chefs militaires conservaient un corps de logis principal bâti dans le style de l'architecture aristocratique, alors que la vie quotidienne des maisons s'organisait davantage autour des pavillons de jardins. Les édifices de plaisance devenaient le lieu des banquets, des 
spectacles de danse, des concours de poésie, bientôt des réunions de thé. Le théâtre nō, qui est né à cette époque, apparaît lors de fêtes données dans les grandes demeures. C'est là, depuis les vérandas, que les seigneurs et les nobles pouvaient contempler, à la nuit tombée, les représentations de théâtre jouées sur des scènes dressées au milieu des jardins. Ces usages nouveaux ont modifié en profondeur l'organisation des palais et des jardins.

Dans le même temps, la collection d'œuvres d'art est devenue une activité particulièrement en vogue. Les inventaires de collections dressés aux $\mathrm{XV}^{\mathrm{e}} \mathrm{et} \mathrm{XVI}^{\mathrm{e}}$ siècles dans les palais des shoguns Ashikaga attestent l'importance des pièces chinoises (Kundaikan sōchō-ki 君台観左右帳記 [Recueil en deux parties des œuvres de la résidence princière], Gunsho ruiju, vol. 12-361). Afin de permettre l'exposition des « objets renommés », meibutsu 名物, les architectes ont alors conçu de nouveaux éléments décoratifs, intégrés à l'ossature des édifices. Des alcôves, tokonoma 床の間, où l'on accrochait les peintures, assorties d'étagères ornementales, chigaidana 違棚, des bibliothèques, shoin 書院, ont été installées dans les pièces de réception afin d'exposer les précieux objets de collection (Okazarisho 御飾書 [Le livre des ornementations], Gunsho ruiju, vol. 12-361). Au XVI siècle, la disposition des alcôves et des étagères décoratives en est venue à déterminer la place, selon l'ordre hiérarchique, des personnes présentes dans une pièce, lors d'une audience officielle ou lors d'activités moins formelles comme une rencontre de thé. Ces éléments d'architecture n'étaient toutefois qu'une enveloppe et leur l'importance résultait avant tout de la valeur des objets que l'on y déposait. L'étude des peintures de paysage, des brûle-parfums, des paysages de pierres présentés sur des plateaux, des bronzes et des compositions florales montre que le symbolisme religieux autrefois réservé aux paysages miniatures des jardins est alors fréquemment associés aux ornements intérieurs d'un palais.

L'habitat noble du $\mathrm{Xv}^{\mathrm{e}}$ siècle est ainsi à la croisée de ces innovations, auxquelles s'ajoute, dès le $\mathrm{XVI}^{\mathrm{e}}$ siècle, l'influence de l'architecture des pavillons de thé, sukiya 数奇屋 ou chashitsu 茶室, dont les formes, en partie inspirées des représentations chinoises d'un ermite vivant retiré du monde, ont modifié en profondeur le formalisme qui avait prévalu jusque-là dans l'habitat noble. Cette histoire architecturale et paysagère, dont procède une formulation purement japonaise d'éléments inspirés à la fois de l'architecture locale que de la tradition chinoise du lettré, a ainsi esquissé les formes de l'habitat noble de la période pré-moderne. 